\title{
KWH METER DIGITAL DENGAN SISTEM PRABAYAR BERBASIS IC BL0932 DAN MIKROKONTROLER 38024
}

\author{
Bimo Kristianto Lukito, Heru Winarno \\ Program Studi Diploma III Teknik Elektro \\ Fakultas Teknik Universitas Diponegoro
}

\begin{abstract}
Bimo Kristianto Lukito, Heru Winarno, in paper prepaid digital KWH meter based on IC BL0932 and microcontroller 38024 explain that an analog meter $k W h$ used by PLN placed in homes. Has several drawbacks, including the effects of age and weather making its numbers less opaque and can be seen. Read error resulted in the use of electrical power and recording electricity bills electricity that could harm users. To overcome these problems made a digital $\mathrm{kWh}$ meter with prepaid systems, with the advantages of digital display are lit and large enough. The system replaced the way payments are prepaid, by using an electronic prepaid card replacement bills. Digital $\mathrm{kWh}$ meter is controlled by a microcontroller with type 38024 and type IC BL0932 uses a function to read the voltage and current (with load reaches 1300 watts) to determine the energy used in home installations using the LCD as a data viewer that the amount of electrical energy used at home . The payment system by purchasing an electronic voucher, containing a digital scale (functioning as a pulse) as a comparison of the amount of energy used. This system automatically decides if the magnitude of the voltage reaches a value of 0 .
\end{abstract}

Keywords : digital kWh meter, IC BL0932, microcontroller 38024

\section{PENDAHULUAN \\ Latar Belakang}

Sebuah kWh meter analog (yang biasa dipakai PLN) cenderung mempunyai beberapa kelemahan, diantaranya :

- Pengaruh usia dan cuaca membuat penunjuk angka buram dan kurang bisa dilihat.

- Angka yang buram ini mengakibatkan petugas bisa mengalami kesalahan baca penggunaan daya listrik.

- Kesalahan baca dapat mengakibatkan kesalahan catatan (salah entry data) dan akhirnya mengakibatkan kesalahan tagihan listrik.

Kesalahan ini akan berlanjut bila tidak disadari oleh petugas. Pada saat kesalahan diketahui biasanya sudah cukup parah untuk diperbaiki karena pengukuran beban yang kumulatif. Kesalahan diatas dapat diatasi oleh $\mathrm{kWh}$ meter digital sistem prabayar, yaitu dengan :

- Indikator display digital menggunakan seven segment dapat menyala dan berukuran besar.

- Terdapat sistem prabayar yang menggunakan kartu voucher elektronik yang menggantikan cara pembayaran umumnya.

\section{Ruang Lingkup Kerja Dan Tujuan}

Ruang lingkup kerja dari tugas akhir ini adalah membuat $\mathrm{kWh}$ meter sistem parabayar dengan beban sampai dengan 1300 watt menggunakan IC BL0932 dan Mikrokontroller 38024.

Tujuan dari pembuatan sistem KWh Meter Digital Dengan Sistem Prabayar Berbasis IC
BL0932 Dan Mikrokontroller 38024 dapat dijelaskan sebagai berikut :

- Merancang dan membuat sistem kWh meter digital dengan sistem prabayar.

- Merancang perangkat keras dan cara kerja dari $\mathrm{kWh}$ meter digital dengan sistem prabayar.

\section{Perumusan Masalah}

Dalam perancangan dan realisasi $\mathrm{kWh}$ Meter Digital Dengan Sistem Prabayar Berbasis IC BL0932 Dan Mikrokontroller 38024 muncul beberapa permasalahan, yaitu :

- Merancang blok - blok diagram yang akan dibuat dengan memperhatikan pengembangan yang dilakukan.

- Merancang rangkaian untuk setiap blok diagram dengan memperhatikan pengembangan yang akan dilakukan.

- Membuat cara kerja dari sistem kWh meter digital dengan sistem prabayar.

- Merancang dan membuat box agar mempermudah pengoperasian.

\section{LANDASAN TEORI \\ Tahanan Shunt}

Yang dimaksud dengan Tahanan Shunt adalah resistor yang digunakan untuk mengukur besaran arus dari tegangan PLN, Dimana besaran dari resistor mempengaruhi keakuratan pengukuran. Beberapa pertimbangan yang harus diperhatikan dalam pemilihan tahanan shunt :

- memperkecil disipasi daya dari tahanan shunt.

- tingginya disipasi daya menimbulkan permasalahan panas pada tahanan shunt yang 
bisa mengakibatkan error yang cukup berpangaruh pada saat beban besar.

- kemampuan untuk mengukur dimana bila tahanan shunt terlalu besar tidak mampu untuk mengukur beban kecil.

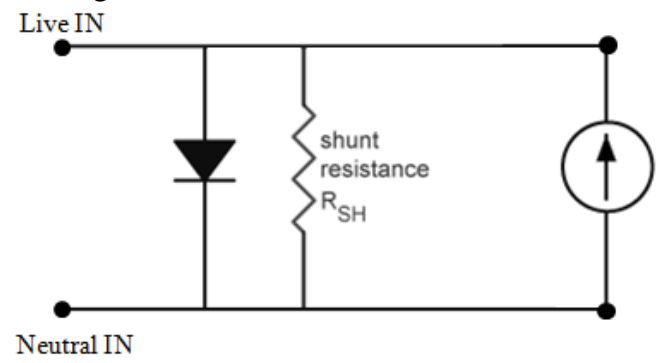

Gambar 1. Tahanan Shunt

Relay

Relay merupakan bentuk hambatan terdiri atas titik-titik kontak bawah dengan gulungan kumparannya tidak bergerak dan titik kontak bagian atas yang bergerak. Prinsip kerja hambatan adalah menghubungkan titik-titik kontak bagian bawah dengan titik bagian atas yaitu terletak gulungan kumparan dialiri arus listrik yang timbul elektromagnet.

Bagian titik kontak dibagi menjadi 2 bagian yaitu bagian kontak utama dan kontak bantu yaitu :

- Bagian kontak utama gunanya untuk menghubungkan dan memutuskan arus listrik bagian yang menuju beban/pemakai.

- Bagian kontak bantu gunanya untuk menghubungkan dan memutuskan arus listrik ke bagian yang menuju bagian pengendali.

Kontak Bantu mempunyai 2 kontak yaitu kontak hubung (NC) dan kontak putus (NO) menandakan masing-masing kontak dan gulungan kumparan.

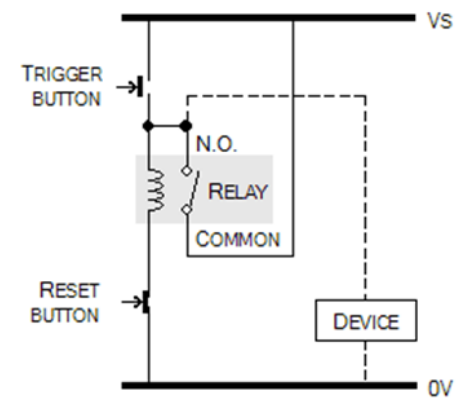

Gambar 2. Sirkuit Relay

\section{Kapasitor Dropper}

Jika kita memiliki sebuah rangkaian yang hanya memerlukan catuan beberapa milliamps maka untuk menghindari biaya transformator tinggi penulis menggunakan sirkuit kapasitor dropper. Kapasitor dropper ini mampu tahan terhadap panas jika dibandingkan dengan sirkuit resistor dropper yang menghasilkan panas. Dengan menggunakan kapasitor dropper power supply maka rangkaian menjadi sederhana dan dapat dikemas dengan lebih kompak tidak makan tempat.

\section{Dioda Zener}

Dioda zener adalah diode yang memiliki karakteristik menyalurkan arus listrik mengalir ke arah yang berlawanan jika tegangan yang diberikan melampaui batas "tegangan tembus" (breakdown voltage) atau "tegangan zener". Ini berlainan dari diode biasa yang hanya menyalurkan arus listrik ke satu arah.

Dioda yang biasa tidak akan mengalirkan arus listrik untuk mengalir secara berlawanan jika dicatu-balik (reverse-biased) di bawah tegangan rusaknya. Jika melampaui batas tegangan operasional, diode biasa akan menjadi rusak karena kelebihan arus listrik yang menyebabkan panas. Namun proses ini adalah reversibel jika dilakukan dalam batas kemampuan. Dalam kasus pencatuanmaju (sesuai dengan arah gambar panah), diode ini akan memberikan tegangan jatuh (drop voltage) sekitar 0.6 Volt yang biasa untuk diode silikon. Tegangan jatuh ini tergantung dari jenis diode yang dipakai.

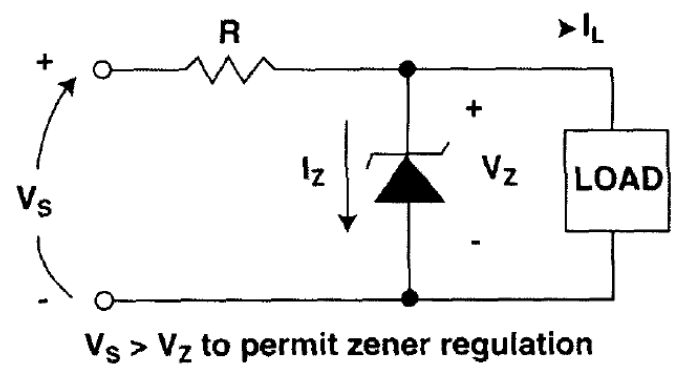

Gambar 3. Rangkaian Dioda Zener

\section{Voltage Regulator LM317}

Voltage regulator merupakan sebuah pengatur tegangan yang dirancang secara otomatis untuk menjaga tingkat tegangan konstan. Sebuah regulator tegangan sederhana dapat menjadi "feedforward" desain atau dapat mencakup loop kontrol umpan balik negatif. Memungkinkan untuk digunakan dalam mekanisme elektromekanik, komponen elektronik dan dapat digunakan untuk mengatur satu atau lebih tegangan AC / DC. Voltage regulator banyak digunakan dalam catuan listrik pada produk komputer yang memerlukan tegangan DC yang stabil untuk procecor dan elemen lainnya.

LM317 merupakan adjustable voltage regulator yang mampu memasok arus lebih dari 100 $\mathrm{mA}$ dengan range $1.2 \mathrm{~V}-37 \mathrm{~V}$ regulator output. Hal ini sangat mudah digunakan dan hanya membutuhkan dua resistor eksternal untuk mengatur tegangan output. Pengaturan beban lebih baik dibandingkan dengan regulator standar. Selain kinerja yang lebih tinggi dari regulator tetap, LM317 menawarkan perlindungan yang lebih baik 
karena dapat memberikan perlindungan terhadap panas khususnya pada IC chip. Semua sirkuit tetap berfungsi penuh bahkan jika terminal penyesuaian terputus. Biasanya, tidak diperlukan kapasitor kecuali perangkat terletak lebih dari 6 inci dari kapasitor filter input. Output opsional kapasitor dapat ditambahkan untuk meningkatkan respon. Selain mengganti regulator tetap, LM317 ini berguna dalam berbagai aplikasi lainnya. Karena regulator adalah "mengambang" dan hanya melihat tegangan input diferensial-untuk-output, pasokan beberapa ratus volt dapat diatur selama diferensial input-ke-output maksimum tidak terlampaui. Selain itu membuat switching yang diatur secara sederhana, regulator output yang diprogram, atau dengan menghubungkan resistor tetap antara penyesuaian dan output. LM317 dapat digunakan sebagai pengatur presisi.

\section{Mikrokontroler H8 / 38024.}

H8 / 38024 buatan Renesas Technology Corp merupakan single chip micro computer berkecepatan tinggi yang dilengkapi dengan peripheral system function antara lain :

- 6 timers

- 2 channel 10 bit Pulse Width Modulator

- 1 serial communication interface

- 1 Analog Digital Converter

- 32 Kbyte ROM

- 1 Kbyte RAM

- LCD driver / controller

Lengkapnya fungsi - fungsi ini menyebabkan Grup H8/38024 cocok untuk aplikasi yang memerlukan konsumsi daya rendah dan termasuk tampilan LCD.

\section{Fitur H8/38024.}

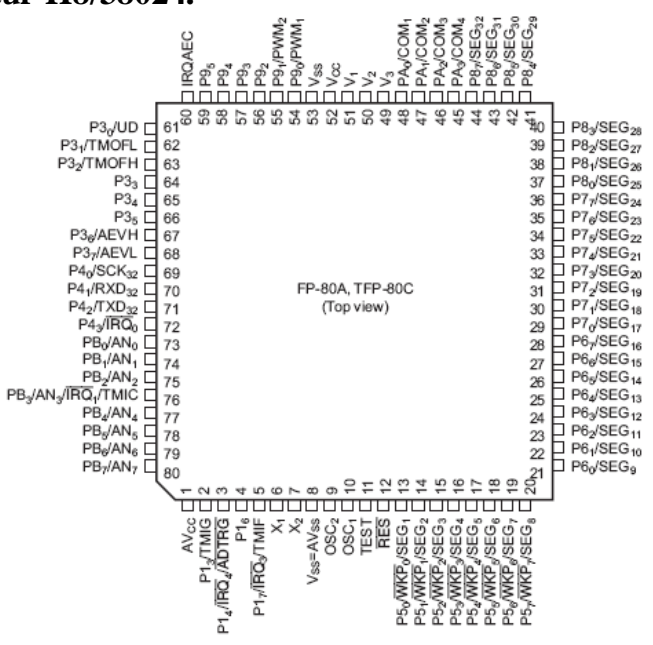

Gambar 5. Diagram Pin 38024

- $\quad$ CPU.

Berkecepatan tinggi, general-register arsitekturnya terdiri dari enam belas 8-bit register (dapat digunakan sebagai delapan bit 16-register), max. operasi kecepatan: $8 \mathrm{MHz}$, set Instruksi kompatibelnya terdiri dari instruksi panjang 2 byte atau 4 byte, mempunyai operasi aritmatika dasar antara register, mempunyai MOV instruksi untuk transfer data antara memori dan register, mempunyai instruksi khas (multiply ( 8 bit x 8 bit), divide (16 bit $\div 8$ bit), bit akumulator).

- Interupsi.

Mempunyai 22 sumber interupsi yang terdiri dari 13 interupsi eksternal dan 9 interupsi sumber internal.

- Clock pulse generator.

Mempunyai dua generator pulsa on-chip yaitu sistem clock pulse generator $(1,0-16 \mathrm{MHz})$ dan subclock pulsa generator $(32,768 \mathrm{kHz})$.

- Power-down mode.

Mempunyai tujuh power-down mode yaitu mode sleep (kecepatan tinggi), mode sleep (kecepatan menengah), mode standby, mode watch, mode subsleep, mode subactive, mode aktif (kecepatan menengah).

- Memori.

Mempunyai large on-chip memori (32-Kbyte ROM, RAM 1-Kbyte).

- $\quad \mathrm{I} / \mathrm{O}$ ports.

Mempunyai 66 pin yang terdiri dari 51 pin I/O, 9 pin masukan, 6 keluaran pin.

- Timers.

Mempunyai enam on-chip timer yang terdiri dari timer J: 8-bit timer, asynchronous event counter: 16-bit timer, timer $\mathrm{C}$ : 8-bit timer, timer F: 16-bit timer, timer G: 8-bit timer, watchdog timer.

- Interface.

SCI3: 8-bit sinkron / asinkron antarmuka serial.

- 10-bit PWM .

Dapat digunakan sebagai 10-bit D/A converter dengan menghubungkan ke lowpass eksternal menyaring.

- $\mathrm{A} / \mathrm{D}$ converter.

Menggunakan tangga resistensi berupa 8channel analog input pin dan konversi waktu: $31 / \varphi$ atau $62 / \varphi$ per channel.

- LCD controller.

Dilengkapi dengan maksimum 32 pin dan empat segmen umum pin. Mempunyai pilihan empat siklus (statis, 1/2, 1/3, atau 1/4) dan segmen pin dapat diaktifkan untuk tujuan umum di 4-bit unit. 


\section{IC BL0932}

IC BL0932 adalah chip utama yang banyak digunakan untuk proses kalkulasi $\mathrm{kWh}$ meter. BL0932 mempunyai linearitas yang lebih baik, luas jangkauan pengukurannya dinamis terhadap pergeseran potensial, serta tersedia fitur anti pencurian daya listrik, sehingga $\mathrm{kWh}$ meter yang menggunakan IC ini memiliki keandalan yang lebih baik. BL0932 adalah IC khusus digunakan untuk elektronik statis watt-jam meter. Menggunakan silikon penghalang proses BICMOS dengan maju sirkuit, pengukuran ganda dari watt, yang sangat baik kinerja, aman \& terpercaya. Rangkaian ini dikemas plastik / keramik dengan 20 pin. Fitur dari IC BL0932 yaitu :

- memiliki fungsi nyata anti-pencurian listrik.

- mempunyai ketepatan pengukuran untuk sinyal positif dan negatif daya listrik.

- linearitas baik pada jangkauan pengukuran yang luas.

- $\quad$ output pulsa yang cepat dalam pemrosesan data computer.

- dapat digunakan untuk pengukuran 1 phasa dan 3 phasa.

- mempunyai keandalan life time $>20$ tahun.

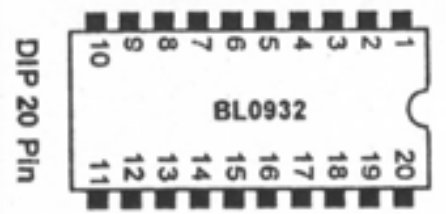

Gambar 6. Diagram Pin BL0932

\section{Optocoupler}

Optocoupler merupakan gabungan dari LED infra merah dengan fototransistor yang terbungkus menjadi satu chips. Cahaya infra merah termasuk dalam gelombang elektromagnetik yang tidak tampak oleh mata telanjang. Sinar ini tidak tampak oleh mata karena mempunyai panjang gelombang berkas cahaya yang terlalu panjang bagi tanggapan mata manusia. Sinar infra merah mempunyai daerah frekuensi 1 x $1012 \mathrm{~Hz}$ sampai dengan 1 x $1014 \mathrm{GHz}$ atau daerah frekuensi dengan panjang gelombang $1 \mu \mathrm{m}-1 \mathrm{~mm}$. LED infra merah ini merupakan komponen elektronika yang memancarkan cahaya infra merah dengan konsumsi daya sangat kecil. Jika diberi prasikap maju, LED infra merah yang terdapat pada optocoupler akan mengeluarkan panjang gelombang sekitar 0,9 mikrometer.

Proses terjadinya pancaran cahaya pada LED infra merah dalam optocoupler adalah sebagai berikut. Saat dioda menghantarkan arus, elektron lepas dari ikatannya karena memerlukan tenaga dari catu daya listrik. Setelah elektron lepas, banyak elektron yang bergabung dengan lubang yang ada di sekitarnya (memasuki lubang lain yang kosong). Pada saat masuk lubang yang lain, elektron melepaskan tenaga yang akan diradiasikan dalam bentuk cahaya, sehingga dioda akan menyala atau memancarkan cahaya pada saat dilewati arus. Cahaya infra merah yang terdapat pada optocoupler tidak perlu lensa untuk memfokuskan cahaya karena dalam satu chip mempunyai jarak yang dekat dengan penerimanya. Pada optocoupler yang bertugas sebagai penerima cahaya infra merah adalah fototransistor. Fototransistor merupakan komponen elektronika yang berfungsi sebagai detektor cahaya infra merah. Detektor cahaya ini mengubah efek cahaya menjadi sinyal listrik, oleh sebab itu fototransistor termasuk dalam golongan detektor optik. Fototransistor memiliki sambungan kolektor-basis yang besar dengan cahaya infra merah, karena cahaya ini dapat membangkitkan pasangan lubang elektron. Dengan diberi prasikap maju, cahaya yang masuk akan menimbulkan arus pada kolektor. Fototransistor memiliki bahan utama yaitu germanium atau silikon yang sama dengan bahan pembuat transistor. Tipe fototransistor juga sama dengan transistor pada umumnya yaitu PNP dan NPN. Perbedaan transistor dengan fototransistor hanya terletak pada rumahnya yang memungkinkan cahaya infra merah mengaktifkan daerah basis, sedangkan transistor biasa ditempatkan pada rumah logam yang tertutup. Bentuk fisik dan simbol optocoupler dapat dilihat pada gambar 7 .

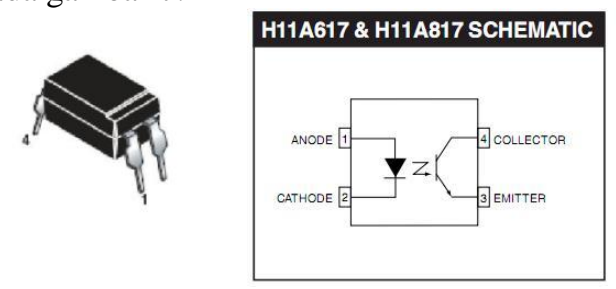

Gambar 7. Bentuk Fisik Dan Symbol Sensor Optocoupler

\section{PERANCANGAN DAN REALISASI}

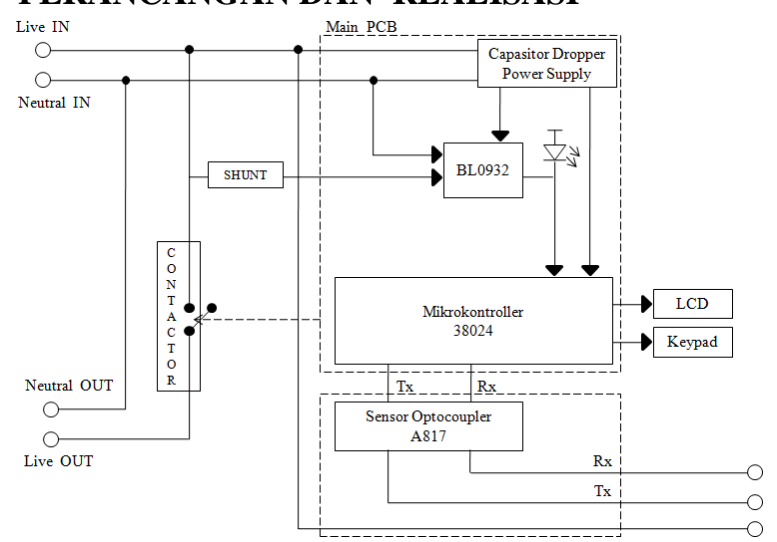

Gambar 8. Diagram Blok KWh Meter Digital Prabayar 
Input, Output dan Line Terminal.

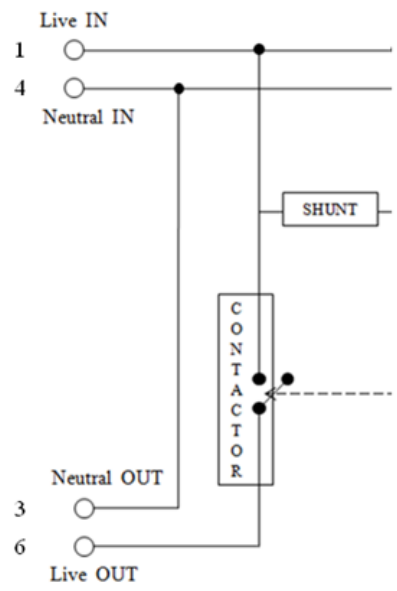

Gambar 9. Input, Output dan Line Terminal

Input dari PLN akan masuk melalui terminal 1 (phase) dan 4 (netral) sedangkan output beban akan keluar melalui terminal 3 (netral) dan 6 (phase), dalam hal ini menggunakan pengkawatan assymetrical. Kemudian pada bagian input, output ini juga diberikan sebuah relay (latching relay) KG120.

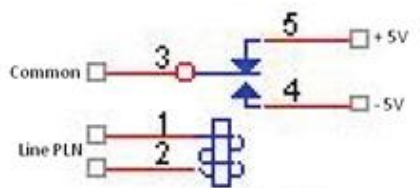

RELAY

Gambar 10. Symbol Latching Relay KG120

Latch relay ini akan bekerja apabila mendapat perintah dari mikrokontroler yaitu dalam hal :

- Terjadi beban lebih

- Temper switch open

- Kesalahan Memory

- Menampilkan kWh minus

Adapun untuk perhitungan rangkaian $\mathrm{R}$ Shunt adalah sebagai berikut :

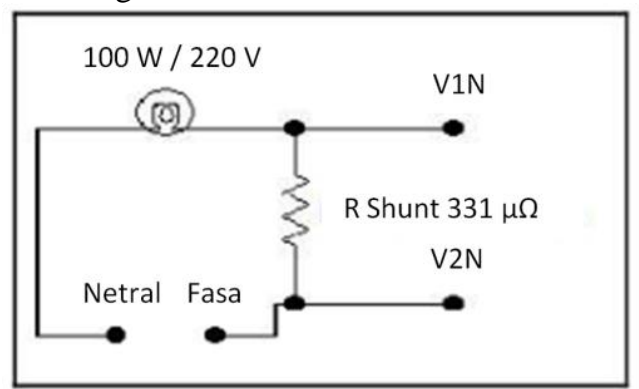

Gambar 11. Rangkaian R Shunt

\subsection{Bagian Pengali.}

Penggunakan BL0932 untuk membentuk kWh meter satu phase spesifikasi : $\mathrm{I}=6 \mathrm{~A}, \mathrm{C}=$ 1600 P/kWh. BL0932 akan mengukur baik daya positif maupun daya negatif secara akurat pin 11 adalah ground dari chip, pin $11 \mathrm{Vss}(-5 \mathrm{~V})$, pin 17 Vdd $(+5 \mathrm{~V})$

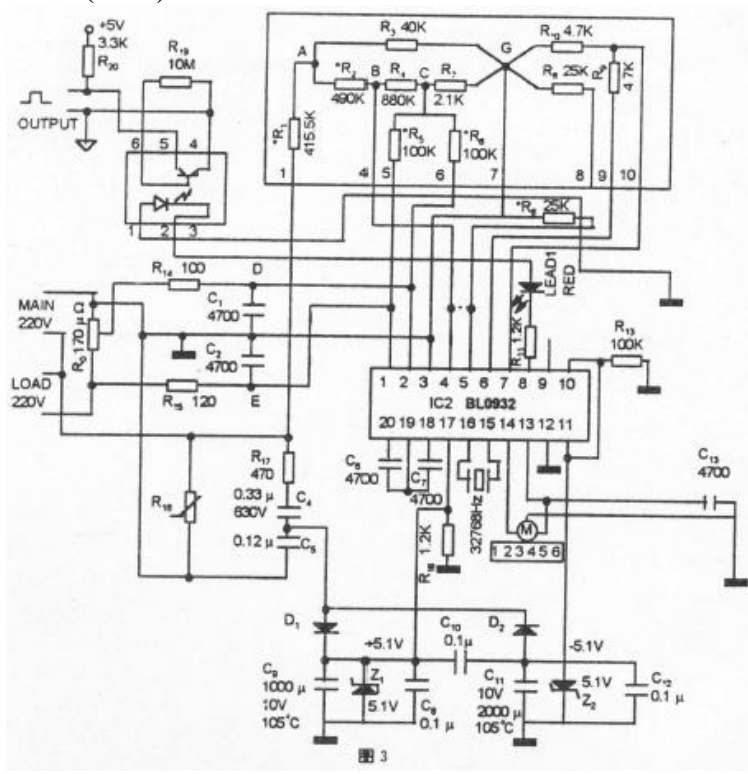

Gambar 12. Rangkaian Proses Kalkulasi KWh Meter Menggunakan IC BL0932

\subsection{Pemrosesan Dan Kontrol.}

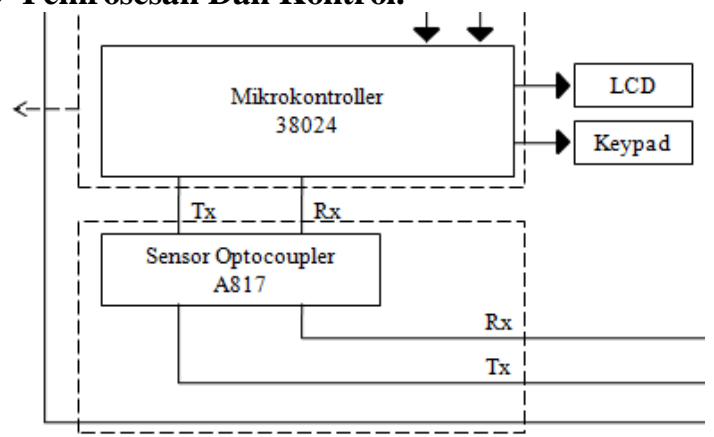

Gambar 13. Bagian Pemrosesan Dan Kontrol

Mikrokontroller berfungsi sebagai pengendali utama dari sistem yang dirancang. Jenis mikrokontroller yang digunakan pada perancangan ini adalah mikrokontroller 38024 produksi Renesas. Pada perancangan ini dipilih mikrokontroller 38024 karena :

- CPU Berkecepatan tinggi.

- General-register arsitekturnya terdiri dari enam belas 8-bit register (dapat digunakan sebagai delapan bit 16-register).

- Max. operasi kecepatan: $8 \mathrm{MHz}$.

- Set Instruksi kompatibelnya terdiri dari instruksi panjang 2 byte atau 4 byte.

- Mempunyai operasi aritmatika dasar antara register. 
- Mempunyai large on-chip memori (32-Kbyte ROM, RAM 1-Kbyte).

- Mempunyai 66 pin I/O port yang terdiri dari 51 pin I/O, 9 pin masukan, 6 keluaran pin.

- Mempunyai LCD driver dan controller.

- Konsumsi daya rendah.

Mikrokontroller 38024 dalam proyek ini penggunaannya adalah untuk menampilkan hasil output dari IC BL0932 berupa jumlah kWh yang terpakai, untuk memproses operasi prabayar, sebagai penyimpan data, memberi kontrol pengamanan, menerima perintah dari keypad lalu menampilkan ke LCD. Untuk dapat mengakses mikrokontroler tersebut maka dibuat serial interface comms yang terdiri dari dua buah optocoupler tipe A817 dan dua buah dioda seri 023. A817 digunakan dalam pembuatan alat ini karena biasa digunakan untuk power supply regulator, input digital logic dan input mikrokontroler.

\subsection{Rangkaian Power Supply.}

Pada proyek ini menggunakan rangkaian kapasitor dropper power supply untuk mendapatkan catuan DC yang konstan untuk keperluan operasi mikrokontroler 38024 dan IC BL0932. Rangkaian ini terdiri dari sebuah kapasitor vishay F1772 kelas $\mathrm{X} 2$, zener dioda sebagai pembatas tegangan tipe BZG03C dan komponen pendukung lainnya. Untuk catuan 5 Volt bisa dilihat pada gambar dibawah ini :

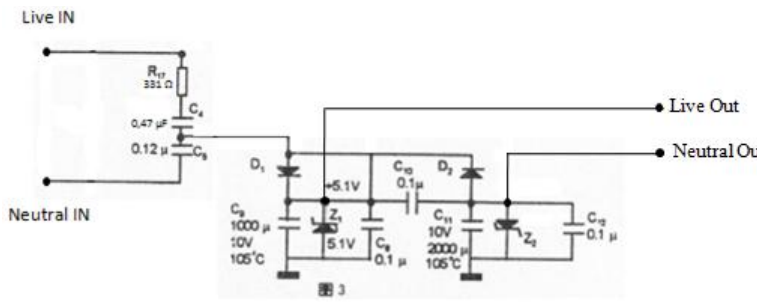

Gambar 14. Rangkaian Power Supply +5 V dan -5 V

Besaran C1 kapasitansinya dalam kisaran $0.47 \mathrm{uF}$ sampai $1.0 \mathrm{uF}$ tergantung dari kebutuhan. Dimana semakin tinggi kapasitansi, semakin tinggi kemampuannya. Kapasitor dropper biasanya menggunakan qualifikasi X2. Kelebihan Kapasitor $\mathrm{X} 2$ dibandingkan dengan keramik yaitu :

- berbahan dasar metal dan prophelyn

- dapat merepair sendiri (shelf healing) bila terjadi lonjakan tegangan

- kapasitansi sampai $1 \mathrm{uF}$ sedangkan kapasitor keramik hanya mampu maksimal sampai dengan $0.22 \mathrm{uF}$

- lebih stabil terhadap perubahan temperature bila failure open sirkuit, sedang keramik short sirkit sehigga lebih aman

\section{Pemrograman.}

Perencanaan software sangat berhubungan dengan rancangan hardware dimana diantaranya berhubungan antara desain counter dan display, desain prabayar dan pemutus tegangan. Perencanaan program pada sistem $\mathrm{kWh}$ meter prabayar ini menggunakan bahasa $\mathrm{C}++$. Flowchart program utama dari proyek ini adalah sebagai berikut :

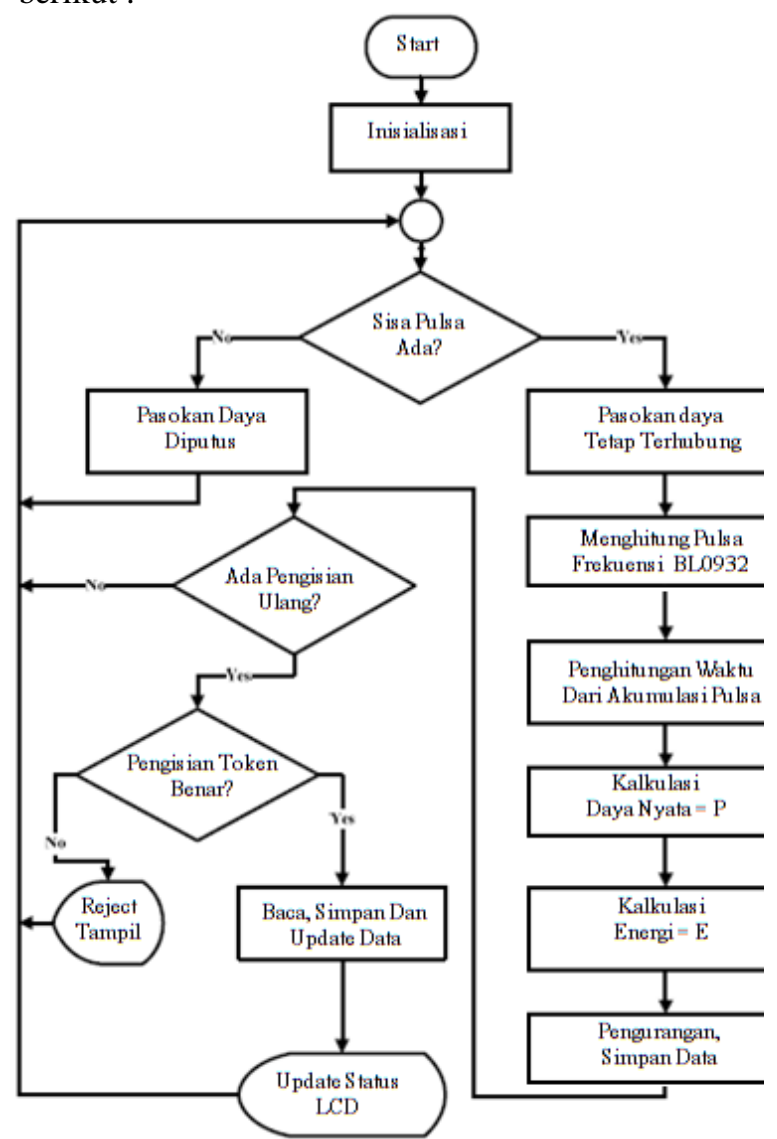

Gambar 15. Flowchart Program Utama

\section{PENUTUP}

3.1 Kesimpulan.

- KWh meter prabayar merupakan alat pengukur daya listrik yang menggunakan sistem pulsa. Dengan sistem ini, pelanggan diuntungkan karena dapat meminimalisir kesalahan dalam pencatatan ketika kita akan membayar listrik.

- Pelanggan dapat mengontrol sendiri penggunaan listrik yang telah ataupun yang akan kita pergunakan. Hal ini pun mempermudah pihak PLN dalam melakukan pengecekan atau pun pendataan.

- IC BL0932 mempunyai ketepatan pengukuran untuk sinyal positif dan negatif serta jangkauan pengukuran yang luas sehingga chip tersebut dapat diandalkan.

- Mikrokontroler 38024 merupakan single chip mikrokomputer berkecepatan tinggi.

\subsection{Saran.}


- Diperlukan pengujian lebih lanjut untuk mngetahui kelemahan pada $\mathrm{kWh}$ meter ini agar lebih handal dan lebih akurat hasil pembacaan meternya.

- Untuk dapat memperbaiki pengujian linearitas diperlukan penambahan digit dibelakang koma, tidak hanya 2 digit melainkan 3 atau 4 .

\section{DAFTAR PUSTAKA}

1. Hadi, Sutrisno. 1984. Bimbingan Menulis Skripsi Thesis Jidil 2. Yogyakarta : Andi Offset.

2. Malvino, Barmawi. 1995. Prinsip - Prinsip Elektronika. Jakarta : Erlangga.

3. Owen, Bishop. 2004. Dasar - Dasar Elektronika. Jakarta : Erlangga.

4. http://www.scribd.com/doc/38673907/PrinsipDasar-Kwh-Meter

5. http://id.wikipedia.org/wiki/Dioda_Zener

6. http://en.wikipedia.org/wiki/Voltage_regulator

7. http://www.scribd.com/doc/46778096/6$\underline{\text { Keypad }}$

8. http://www.kgtechnologies.net : datasheet Latch Relay KG120

9. http:// www.national.com : datasheet LM317L 3-Terminal Adjustable Regulator

10. http://www.renesas.com : datasheet User's Manual H8/38024

11. http://www.belling.com.cn : datasheet Dual Measurement Watt-Hour Meter IC BL0932 